Hope College

Hope College Digital Commons

Faculty Publications

6-2007

\title{
Brainstem Cholinergic Modulation of Muscle Tone in Infant Rats
}

Andrew J. Gall

University of lowa, gall@hope.edu

Amy Poremba

University of lowa

Mark S. Blumberg

University of lowa

Follow this and additional works at: https://digitalcommons.hope.edu/faculty_publications

Part of the Behavioral Neurobiology Commons, and the Biological Psychology Commons

\section{Recommended Citation}

Repository citation: Gall, Andrew J.; Poremba, Amy; and Blumberg, Mark S., "Brainstem Cholinergic Modulation of Muscle Tone in Infant Rats" (2007). Faculty Publications. Paper 1507.

https://digitalcommons.hope.edu/faculty_publications/1507

Published in: European Journal of Neuroscience, Volume 25, Issue 11, June 1, 2007, pages 3367-3375.

Copyright @ 2007 Wiley.

This Article is brought to you for free and open access by Hope College Digital Commons. It has been accepted for inclusion in Faculty Publications by an authorized administrator of Hope College Digital Commons. For more information, please contact digitalcommons@hope.edu. 


\title{
BRAINSTEM CHOLINERGIC MODULATION OF MUSCLE TONE IN INFANT RATS
}

\author{
Andrew J. Gall, Amy Poremba, and Mark S. Blumberg \\ Program in Behavioral and Cognitive Neuroscience, Department of Psychology, University of lowa, \\ lowa City, IA, 52242, USA
}

\begin{abstract}
In week-old rats, lesions of the dorsolateral pontine tegmentum (DLPT) and nucleus pontis oralis (PnO) have opposing effects on nuchal muscle tone. Specifically, pups with DLPT lesions exhibit prolonged bouts of nuchal muscle atonia (indicative of sleep) and pups with PnO lesions exhibit prolonged bouts of high nuchal muscle tone (indicative of wakefulness). Here we test the hypothesis that nuchal muscle tone is modulated, at least in part, by cholinergically mediated interactions between these two regions. First, in unanesthetized pups, we found that chemical infusion of the cholinergic agonist carbachol $(22 \mathrm{mM}, 0.1 \mu \mathrm{L})$ within the DLPT produced high muscle tone. Next, chemical lesions of the nucleus pontis oralis $(\mathrm{PnO})$ were used to produce a chronic state of high nuchal muscle tone, at which time the cholinergic antagonist scopolamine $(10 \mathrm{mM}, 0.1 \mu \mathrm{L})$ was infused into the DLPT. Scopolamine effectively decreased nuchal muscle tone, thus suggesting that lesions of the PnO increase muscle tone via cholinergic activation of the DLPT. Using 2deoxyglucose (2-DG) autoradiography, metabolic activation throughout the DLPT was observed after PnO lesions. Finally, consistent with the hypothesis that PnO inactivation produces high muscle tone, infusion of the sodium channel blocker, lidocaine (2\%), into the PnO of unanesthetized pups produced rapid increases in muscle tone. We conclude that, even early in infancy, the DLPT is critically involved in the regulation of muscle tone and behavioral state and that its activity is modulated by a cholinergic mechanism that is directly or indirectly controlled by the PnO.
\end{abstract}

\section{Keywords}

Acetylcholine; carbachol; 2-deoxyglucose; autoradiography; EMG; development

Infant rats cycle more rapidly than adults between sleep and wakefulness (Kleitman \& Engelmann, 1953; Blumberg et al., 2005). One of the challenges for sleep researchers is to reveal the neural circuits that generate this cyclicity as well as the processes underlying the dramatic developmental changes that mediate the transition to the more stable and persistent sleep and wake durations characteristic of adults (Lo et al., 2002; Lo et al., 2004; Blumberg et al., 2005).

We have learned much in recent years about the brainstem mechanisms that produce sleep and wakefulness in infants (Karlsson et al., 2005; Karlsson \& Blumberg, 2005). Specifically, we recently reported that the dorsolateral pontine tegmentum (DLPT), which includes the laterodorsal tegmental nucleus (LDT), the pedunculopontine tegmental nucleus (PPT), and the parabrachial nucleus (PB), contributes to wakefulness in infant rats (Karlsson et al., 2005). Within the DLPT, neurons were identified that increased their activity during periods of high

Corresponding author: Mark S. Blumberg, Department of Psychology, University of Iowa, Iowa City, IA, 52242, USA, e-mail: E-mail: mark-blumberg@uiowa.edu, Phone: 319.335.2424, Fax: 319.335.0191. 
nuchal muscle tone (indicative of wakefulness) and, when lesions were produced within this region, pups slept $97 \%$ of the time. Conversely, many sleep-related neurons were identified within the nucleus pontis oralis $(\mathrm{PnO})$ and, when lesions were produced within this region, pups were awake $70 \%$ of the time. These reciprocal effects of DLPT and PnO lesions on sleep and wakefulness suggest that interactions between these two areas help mediate transitions between behavioral states in early infancy.

Based on evidence in adults that muscarinic receptors are found throughout the DLPT (Baghdoyan, 1997), we hypothesized that acetylcholine modulates activity in this region to produce the high muscle tone normally indicative of wakefulness. Thus, we predicted that infusing the cholinergic agonist carbachol into the DLPT would induce sustained periods of high muscle tone. We also predicted that blocking cholinergic activity within the DLPT using the cholinergic antagonist scopolamine would inhibit the persistent increase in muscle tone produced by chemical lesions of the PnO. Next, using 2-deoxyglucose (2-DG) autoradiography, we mapped metabolic activity within the brainstem, including the DLPT, after $\mathrm{PnO}$ lesions. Finally, to confirm that it is the inactivation of neurons within the PnO that produces the observed effect on muscle tone, as would be expected from stimulation studies in adults (Hajnik et al., 2000), we infused the sodium channel blocker, lidocaine, into the PnO of unanesthetized pups. All together, our results indicate direct or indirect cholinergic communication between neurons in the PnO and DLPT and suggest that these areas form key parts of the brainstem neural circuit upon which sleep-wake cyclicity in infants depends and upon which the adult system is built.

\section{MATERIALS AND METHODS}

All experiments were performed in accordance with National Institutes of Health guidelines for the care of animals in research and were approved by the Institutional Animal Care and Use Committee of the University of Iowa.

\section{SUBJECTS}

In total, 28 8-10-day-old (P8-10) Sprague-Dawley rats from 26 litters were used. Males and females were equally represented in all experiments. Body weights were $17.0-22.6 \mathrm{~g}$. The pups were raised in litters that were culled to 8 pups within 3 days of birth (day of birth $=\mathrm{P} 0$ ). Mothers and their litters were housed and raised in standard laboratory cages $(48 \mathrm{~cm}$ long $\times$ $20 \mathrm{~cm}$ wide $\times 26 \mathrm{~cm}$ high) in the animal colony at the University of Iowa. Food and water were available to the animals ad libitum. All animals were maintained on a 12-h light-dark schedule with lights on at 7:00 am. All experiments were conducted during the lights-on phase.

\section{PROCEDURE}

\section{Experiment 1: Chemical stimulation of the DLPT with carbachol-Chemical} stimulations were performed using 12 P8-10 rats (equally divided between males and females) from 12 litters. Under isoflurane anesthesia, two bipolar stainless steel electromyogram (EMG) electrodes (50 $\mu \mathrm{m}$ diameter, California Fine Wire, Grover Beach, CA) were inserted bilaterally into the nuchal muscles. (In 8 of these subjects, extraocular EMG data were also collected, as described previously (Seelke \& Blumberg, 2005). These data are not discussed further below because they provided redundant information. In all subsequent experiments, only nuchal EMGs are implanted.) The skull was bleached and then coated with Vetbond (3M, St. Paul, Minnesota, United States) to strengthen the infant's fragile skull. Next, a T-shaped, stainless steel apparatus was attached to the skull using cyanoacrylate adhesive gel in order to secure and stabilize the skull in the stereotaxic apparatus. Finally, the pup was wrapped in gauze to both secure the pup and induce sleep (Corner \& Kwee, 1976). Pups were then placed into a 
humidified incubator maintained at thermoneutrality (i.e., $35^{\circ} \mathrm{C}$ ) for $1-2 \mathrm{~h}$ to recover from surgery.

Using methods described previously (Karlsson \& Blumberg, 2005), the subject was placed in a stereotaxic apparatus (David Kopf Instruments, Tujunga, California, United States) under thermoneutral conditions. Pups were allowed to acclimate for $1 \mathrm{~h}$ prior to stimulation. Nuchal EMG electrodes were connected to a differential amplifier (A-M Systems, Carlsborg, WA), and their signals were amplified (x10,000) and filtered (300-3000 Hz). EMG data were sampled at 12,500 Hz using a digital interface (Model 1401, CED, Cambridge, England), and visualized using Spike2 software (CED, Cambridge, England). Data collection began when the subject exhibited normal sleep-wake cyclicity. For this purpose, sleep was defined as lowamplitude EMG activity with or without the presence of myoclonic twitches, and wake was defined as high-amplitude EMG activity (Karlsson \& Blumberg, 2002; Seelke \& Blumberg, 2005).

A $0.5 \mu l$ 32-gauge microsyringe (Model 7000.5OC; Hamilton Co., Reno, NV) was lowered into the DLPT (coordinates relative to lambda; AP, $-1.2 \mathrm{~mm}$; ML, $\pm 0.4 \mathrm{~mm}$; DV from the cortical surface, $-3.5 \mathrm{~mm}$ ). The syringe remained at the target area for $5 \mathrm{~min}$ before a 5 -min baseline period of data collection began. At the end of the baseline period, the cholinergic agonist carbachol (carbamylcholine chloride, $22 \mathrm{mM}$, Sigma, St. Louis, MO), dissolved in phosphate buffered saline (PBS), or PBS alone, was infused $(0.1 \mu \mathrm{L}$ over $20 \mathrm{~s})$. These parameters for concentration and infusion rate were determined from pilot experiments and previously published work (Xi et al., 2004; Karlsson et al., 2005; Karlsson \& Blumberg, 2005). The order of carbachol and PBS infusion was counterbalanced such that 6 animals received a carbachol infusion first and a PBS infusion 25 min later, and 6 animals received a PBS infusion first and a carbachol infusion 25 min later. Side of infusion was also counterbalanced. Finally, whereas both ipsilateral and contralateral EMG activity was recorded in 4 subjects, either ipsilateral or contralateral activity (but not both) was recorded in the remaining 8 subjects.

Experiment 2: Deactivation of the DLPT using scopolamine-Chemical lesions of the PnO were performed using 6 P8 rats from 6 litters. Pups were prepared for testing as described in Experiment 1. After $1 \mathrm{~h}$ of recovery, pups were placed into the stereotaxic apparatus. A microsyringe (Model 7000.5OC; Hamilton Co., Reno, NV) was lowered into the $\mathrm{PnO}$ (coordinates relative to lambda: AP, $-1.0 \mathrm{~mm}$; ML, $\pm 1.0 \mathrm{~mm}$; DV from the cortical surface, $-6.0 \mathrm{~mm}$ ). The syringe remained at the target site for $5 \mathrm{~min}$ before highly concentrated quisqualic acid $(50 \mathrm{mM}, 0.15 \mu \mathrm{l}$ over $20 \mathrm{~s}$ ) was infused bilaterally into the PnO. The pup was then removed from the stereotaxic apparatus to recover for $3 \mathrm{~h}$ in a humidified incubator maintained at $35^{\circ} \mathrm{C}$. The pup was then returned to the stereotaxic instrument and allowed to acclimate for $1 \mathrm{~h}$ before the test began.

A guide cannula (\#C316-G-5UP, Plastics One, Roanoke, VA) was placed in the brain just dorsal to LDT (coordinates relative to lambda; AP, $-1.2 \mathrm{~mm}$; ML, $\pm 0.4 \mathrm{~mm}$; DV from the cortical surface, $-2.5 \mathrm{~mm}$ ). A microsyringe (Model 7000.5OC; Hamilton Co., Reno, NV) was inserted into the guide cannula and lowered into the LDT (coordinates relative to lambda; AP, $-1.2 \mathrm{~mm}$; ML, $\pm 0.4 \mathrm{~mm}$; DV from the cortical surface, $-3.5 \mathrm{~mm}$ ) and either scopolamine (10 $\mathrm{mM}, 0.1 \mu \mathrm{l}$ over $20 \mathrm{~s}$ ) or PBS was administered. These parameters for concentration and infusion rate were determined from pilot experiments and previously published work (Xi et al., 2004; Karlsson et al., 2005; Karlsson \& Blumberg, 2005). Scopolamine and PBS were both administered to the same animal at 30-min intervals, with the order of drug administration and the side of infusion counterbalanced between subjects. EMG activity was recorded for 5 min before and after infusion. 
Experiment 3: 2-DG mapping of the DLPT after lesions of the PnO-Pups were prepared for testing as described in Experiment 1. As in Experiment 2, P8 rats $(\mathrm{n}=2)$ received bilateral infusions of quisqualic acid $(50 \mathrm{mM}, 0.15 \mu \mathrm{l}$ over $20 \mathrm{~s})$ into the PnO. Control littermates $(n=2)$ received bilateral infusions of saline into the PnO. Littermates were then placed separately in identical double-walled glass testing chambers that were humidified and maintained at thermoneutrality $\left(35^{\circ} \mathrm{C}\right)$. Air flow through each chamber was $300 \mathrm{ml} / \mathrm{min}$. After a 3-h recovery period, each pup was injected intraperitoneally with a glucose analog, 2deoxyglucose (2-DG) radiolabeled with ${ }^{14} \mathrm{C}(18 \mu \mathrm{Ci} / 100 \mathrm{~g}$ of body weight; American Radiolabeled Chemicals, St. Louis, MO) in $0.05 \mathrm{ml}$ of sterile saline. After the injection, nuchal EMG activity was continuously monitored for $45 \mathrm{~min}$ (pups were unrestrained throughout the recovery and testing period). Each pup was then decapitated and its brain quickly removed, placed in hexane at $-35^{\circ} \mathrm{C}$, and then stored at $-80^{\circ} \mathrm{C}$ until analyzed.

Experiment 4: Deactivation of the nucleus pontis oralis using lidocaine-Pups were prepared for testing as described in Experiment 1. After acclimation to the stereotaxic apparatus, head-fixed P8 rats $(n=6)$ received a unilateral infusion $(0.2 \mu \mathrm{L}$ over $15 \mathrm{~s})$ of a $2 \%$ solution of lidocaine (Sigma, St. Louis, MO) dissolved in saline, or saline alone, into the left or right PnO. EMG activity in the ipsilateral and contralateral nuchal muscles was recorded for $5 \mathrm{~min}$ before and after the infusion. Subjects served as their own controls. The order of lidocaine or saline infusion was counterbalanced across subjects, with 30 min between each infusion.

\section{HISTOLOGY}

At the conclusion of each test in Experiment 1, Experiment 2, and Experiment 4, pups were overdosed with sodium pentobarbital and perfused transcardially with PBS followed by $10 \%$ formalin. Brains were post-fixed in the skull for $1-2 \mathrm{~d}$ in a formalin-sucrose solution, removed from the skull, and fixed again for at least $24 \mathrm{~h}$ in fresh formalin-sucrose solution. The brains were then sliced in $50 \mu \mathrm{m}$ sections using a sliding microtome (Model SM $2000 \mathrm{R}$, Leica, Bensheim, Germany). Brain slices were stained using cresyl violet.

For the 2-DG experiment (Experiment 3), brains were sectioned using a cryostat at increments of $40 \mu \mathrm{m}$. Each section was retained, with every fifth section set aside for cresyl violet staining. The remaining sections were quick-dried on glass coverslips, glued on poster board, and exposed to ${ }^{14} \mathrm{C}$ phosphor imaging screens for $36 \mathrm{~h}$ along with ${ }^{14} \mathrm{C}$ standards (Amersham Biosciences, Arlington Heights, IL). The screens were read and digitized by a phosphor imaging system (Cyclone Storage Phosphor System, PerkinElmer Life Sciences, Emeryville, CA). For cresyl violet staining, sections were placed on a glass slide, allowed to dry for $24 \mathrm{~h}$, and soaked in $10 \%$ formalin for $30 \mathrm{~min}$ to fix the tissue before staining.

In Experiment 1, Experiment 2 and Experiment 4, infusion sites were located by noting syringe tracks. In Experiment 2 and Experiment 3, the rostrocaudal extent of each lesion was determined by examination of sequential brain slices for areas devoid of neurons. Lesions and infusion sites were drawn using image software (Adobe Photoshop 5.5, Adobe, San Jose, CA, USA).

\section{DATA ANALYSIS}

Experiment 1: Chemical stimulation of the DLPT with carbachol-Data were analyzed off-line using Spike2 software. Ipsilateral and contralateral nuchal EMGs were rectified and EMG amplitudes were averaged over 10-s intervals at the following time periods: $1 \mathrm{~min}$ before the infusion and 1,3, and 6 min after the infusion. A site was considered toneproducing if stimulation resulted in an increase in EMG amplitude of at least 2 standard deviations above the average baseline value, as described elsewhere (Karlsson \& Blumberg, 
2005). Percent change in EMG amplitude was calculated at each post-infusion time period in relation to baseline. Group differences were tested using repeated-measures ANOVA and the post hoc test was a paired $t$ test. For this and subsequent experiments, ANOVAs were performed separately for ipsilateral and contralateral muscles. For all tests, alpha was set at 0.05 .

Experiment 2: Deactivation of the DLPT using scopolamine-Ipsilateral and contralateral nuchal EMGs were rectified. EMG amplitudes were averaged over a 10-s interval $30 \mathrm{~s}$ before the infusion of scopolamine and 30,60, 90, and $120 \mathrm{~s}$ after the infusion. Methods for calculating percent change in EMG amplitude and statistical comparisons were identical to those described for Experiment 1.

\section{Experiment 3: 2-DG mapping of the DLPT after lesions of the PnO-}

Autoradiographs of lesioned and sham animals were visually inspected for areas of increased metabolism. The location of lesions within the $\mathrm{PnO}$ was assessed by inspection of the autoradiographs as well as adjacent sections that were stained with cresyl violet.

Experiment 4: Deactivation of the PnO using lidocaine-Data were analyzed as described above for Experiment 2.

For all experiments, means are presented with their standard errors (SE).

\section{RESULTS}

\section{Infusion of carbachol within the DLPT produces high nuchal muscle tone}

To determine whether chemical activation of the DLPT is capable of activating high muscle tone, chemical infusions were performed. Because the DLPT, especially the LDT and PPT, of adult rats is rich in muscarinic receptors (Baghdoyan, 1997), we infused carbachol into the DLPT of unanesthetized, head-fixed pups.

As shown in Figure 1A, infusion of carbachol into the DLPT produced rapid and sustained increases in EMG amplitude in both the ipsilateral and contralateral nuchal muscles. The EMG responses of a single representative pup are depicted in Figure 1B. A repeated-measures ANOVA revealed a significant effect of group on ipsilateral nuchal EMG amplitude $\left(F_{(1,14)}\right.$ $=11.0 ; p<0.01)$ as well as a significant effect of time $\left(F_{(3,42)}=4.7 ; p<0.01\right)$ and a significant group $\times$ time interaction $\left(F_{(3,42)}=4.1 ; p<0.05\right)$. Similarly, a repeated-measures ANOVA revealed a significant effect of group on contralateral nuchal EMG amplitude $\left(F_{(1,14)}=40.9\right.$; $p<0.0001)$ as well as a significant effect of time $\left(F_{(3,42)}=12.6 ; p<0.0001\right)$ and a significant group $\times$ time interaction $\left(F_{(3,42)}=14.0 ; p<0.0001\right)$.

Figure 1C indicates the sites of carbachol and PBS infusion. It can be seen that carbachol infusions produced significant increases in muscle tone when placed in a variety of locations throughout the DLPT, including subcoeruleus, LDT, and PB. In three instances, carbachol infusions were not effective ("misses"); one of these infusions was placed in the central gray adjacent to the fourth ventricle and the other two were placed within the PnO.

In several animals, the induction of high muscle tone by infusion of carbachol into the DLPT was followed within 2-4 min by pronounced convulsions of the limbs, head, and tail, as well as foaming at the mouth. These observations are consistent with previous studies reporting that microinjections of carbachol into the pontine and mesencephalic reticular formation of adult rats produces electroencephalographic seizures, including convulsions (Elazar \& Feldman, 1987; Elazar \& Berchanski, 2000). 


\section{Infusion of scopolamine into the DLPT reverses the effects of PnO lesions on nuchal muscle tone}

Quisqualic acid lesions of the $\mathrm{PnO}$ produce, after several hours, chronically high nuchal muscle tone in infant rats (Karlsson et al., 2005). Given the effects of carbachol infusion described above, we hypothesized that $\mathrm{PnO}$ lesions activate muscle tone by directly or indirectly releasing acetylcholine within the DLPT. Therefore, in this experiment, chemical lesions of the PnO were used to produce high muscle tone, at which time scopolamine was infused into the DLPT. We predicted that scopolamine infusion would reverse the effects of PnO lesions on nuchal muscle tone.

As expected, bilateral quisqualic acid lesions within the PnO resulted in chronically high levels of nuchal muscle tone. Then, as shown in Figure 2A, infusion of scopolamine into the DLPT produced rapid decreases in EMG amplitude in both the ipsilateral and contralateral muscles. The EMG responses of a single representative pup are depicted in Figure 2B. A repeatedmeasures ANOVA revealed a significant effect of group on ipsilateral nuchal EMG amplitude $\left(F_{(1,10)}=6.8 ; p<0.05\right)$ as well as a significant effect of time $\left(F_{(4,40)}=2.6 ; p<0.05\right)$ and a significant group $\times$ time interaction $\left(F_{(4,40)}=5.7 ; p<0.005\right)$. Similarly, a repeated-measures ANOVA revealed a significant effect of group on contralateral EMG amplitude $\left(F_{(1,10)}=9.7\right.$; $p<0.05)$ as well as a significant effect of time $\left(F_{(4,40)}=4.4 ; p<0.005\right)$ and a significant group $\times$ time interaction $\left(F_{(4,40)}=6.0 ; p<0.001\right)$.

Figure $2 \mathrm{C}$ indicates the infusion sites and the extent of the lesions. Most of the scopolamine infusion sites were located within and adjacent to LDT. The lesions were confirmed as being within the PnO.

\section{Metabolic mapping of the DLPT region after PnO lesions}

Bilateral quisqualic acid lesions were produced in the PnO of two P8 rats while littermates received sham lesions. Using nuchal EMG as our measure of sleep and wakefulness (Karlsson et al., 2005; Seelke et al., 2005), data were recorded for $45 \mathrm{~min}$ before the pup was sacrificed and its brain removed. As shown in Figure 3A, the two sham pups were awake 36\% and 25\% of the time, whereas their lesioned littermates were awake $87 \%$ and $89 \%$ of the time, respectively.

The locations of the PnO lesions are depicted in Figure 3B. The bottom row depicts the lesions at the level of the superior colliculus based on sections stained with cresyl violet. The top row presents autoradiographs for sections at the same level. First, we used the cresyl-violet sections to determine the size and location of the lesions; it can be seen that these lesions were located within the PnO. Next, examination of the autoradiographs at corresponding locations within the $\mathrm{PnO}$ reveals regions of inactivation surrounded by halos of activation.

Figure $3 \mathrm{C}$ presents autoradiographs for the two pairs of lesion and sham subjects across four sections within the mesopontine region. First, there is a clear difference in the overall level of activity between the two groups; this finding is consistent with other 2-DG studies of metabolic activity in sleeping and waking subjects (Nakamura et al., 1983; Nofzinger et al., 2002). Second, and most important, the two subjects with PnO lesions exhibited pronounced and specific increases in metabolic activity within the DLPT.

It is important to note that the 2-DG sections were cut at a different angle than those represented in the other figures such that the dorsal regions were farther caudal relative to the ventral regions. Thus, we carefully examined these sections to determine the level at which increased activation occurred. For example, in Figure 3C, for the section that has been labeled, it was determined that the region of heightened metabolic activity (indicated by the white arrow) includes LDT medially and PB laterally. 


\section{Infusion of lidocaine into the PnO produces high nuchal muscle tone}

As shown in Figure 4A, unilateral infusion of lidocaine into the $\mathrm{PnO}$ of unanesthetized, headfixed pups produced rapid and pronounced increases in EMG amplitude in the contralateral nuchal muscle; the EMG responses of a single representative pup are depicted in Figure 4B. A repeated-measures ANOVA revealed a significant effect of group on contralateral EMG amplitude $\left(F_{(1,10)}=12.1 ; p<0.01\right)$, but a non-significant effect of time $\left(F_{(4,40)}=1.2\right)$ and a non-significant group $\times$ time interaction $\left(F_{(4,40)}=1.4\right)$. In contrast, a repeated-measures ANOVA revealed neither a significant effect of group on ipsilateral EMG amplitude $\left(F_{(1,10)}\right.$ $=1.2)$ nor on time $\left(F_{(4,40)}=1.4\right)$; the group $\times$ time interaction was also not significant $\left(F_{(4,40)}=1.3\right)$. Finally, Figure 4C indicates that the infusion sites were located within the PnO.

\section{DISCUSSION}

Fluctuations in skeletal muscle tone provide sufficient information to assess sleep and wakefulness in infants at those ages when other components of sleep (e.g., neocortical EEG) are not yet expressed (Seelke et al., 2005). Indeed, using nuchal atonia alone as an indicator of sleep and wakefulness, state-dependent neurons have been identified in week-old rats throughout the medulla, mesopontine region, hypothalamus, and basal forebrain that fall into the same broad categories that have been identified in adults (Karlsson et al., 2005; Karlsson \& Blumberg, 2005; Mohns et al., 2006). Moreover, lesions of the DLPT and PnO produce increased sleep and wakefulness, respectively (Karlsson et al., 2005).

The present study builds on these earlier reports and implicates the cholinergic system in the modulation of muscle tone in early infancy in rats. First, in Experiment 1, we found that chemical stimulation with the cholinergic agonist, carbachol, across a broad region within the DLPT increased nuchal muscle tone. Next, in Experiment 2, we found that when the PnO was lesioned to produce chronically high muscle tone, infusing scopolamine into the DLPT decreased muscle tone. Together, these findings suggest that the PnO directly or indirectly modulates muscle tone via the release of acetylcholine within the DLPT.

The spread of carbachol and scopolamine after the infusion to distant sites is a concern for the interpretation of our results. We note, however, that the injection volumes used here were small $(0.1 \mu \mathrm{l})$ and many subjects exhibited nuchal EMG responses before the infusions were completed (i.e., within 20 s). Moreover, as shown in Figure 1, three infusions dorsal and ventral to the DLPT, including one adjacent to the fourth ventricle, failed to produce significant increases in muscle tone during the 5-min test. Thus, the effects of the infusions reported here do not appear to be due to diffusion of chemicals to distant sites. Nonetheless, the use of more precise methods will be needed to further delineate the neural mechanisms modulating behavioral state in early infancy.

Consistent with the present findings, it was recently reported (Boissard et al., 2002) that carbachol infusion into the pontine sublaterodorsal nucleus (SLD) of adult rats produces wakefulness. In contrast, carbachol infusion into a homologous location within the pontine reticular formation of cats induces active sleep (Chase \& Morales, 1990; Xi et al., 2004). Although rats and cats may differ with regard to the sleep-promoting effects of carbachol, including the ability of carbachol to trigger REM sleep>, there may be similar non-cholinergic mechanisms within the pontine reticular formation with regard to the generation of sleep and wakefulness in these two species (Xi et al., 1999; Boissard et al., 2002; Boissard et al., 2003; Luppi et al., 2004). In rats, GABA antagonists infused into the SLD produce a state akin to REM sleep (Boissard et al., 2002). Building on this finding, it was recently proposed that the SLD and related nuclei act in opposition to the lateral pontine tegmentum to produce transitions between REM and NREM sleep (Lu et al., 2006). The present results suggest that these lateral pontine nuclei also contribute to the production of wakefulness. 
Based in part on the now-disputed notion that the cholinergic system is essential for the production of REM sleep in adults, and that this system may not yet be functionally mature in early infancy (i.e., before P11 in rats), it was hypothesized (Frank \& Heller, 2003) that infant and adult sleep are qualitatively distinct. This hypothesis, as well as the related contention that infant sleep, however defined, does not rely on executive brain mechanisms, is not supported by recent evidence (Karlsson et al., 2004; Karlsson et al., 2005; Karlsson \& Blumberg, 2005; Mohns et al., 2006). Moreover, the present results, especially those from Experiment 2 in which scopolamine reversed the high muscle tone evoked by PnO lesions, suggest that the cholinergic system is involved in the modulation of wakefulness before P11.

Baghdoyan (1997) established the prevalence of muscarinic receptor subtypes (i.e., $\mathbf{M}_{1}, \mathbf{M}_{2}$, $\mathrm{M}_{3}$ ) within the adult rat pons, including the DLPT. In addition, it has been shown that these muscarinic receptors exhibit high affinity for acetylcholine in neonates (Heacock et al., 1987; Semba, 1992). That there is a dense projection of neurons from the PnO to the DLPT (Semba \& Fibiger, 1992) provides an anatomical foundation for the current finding concerning the excitatory effect of PnO lesions on muscle tone and the reversal of this effect when scopolamine is infused into the DLPT. Finally, cholinergic projections from the DLPT to cholinoceptive cells within the PnO (Shiromani et al., 1988; Jones, 1990; Lai et al., 1993) suggest that there may be reciprocal interactions between these two regions, though such reciprocal interactions were not examined here.

To assess the region of activation during the sustained wakefulness that follows PnO lesions, we used 2-DG autoradiography in Experiment 3. Chemical or sham lesions of the PnO were used to produce littermates that differed substantially in the amount of wakefulness exhibited during the period of 2-DG uptake. In relation to shams, pups with PnO lesions exhibited higher overall levels of metabolic activity in every brain section examined; this is consistent with previous metabolic mapping studies in sleeping and waking monkeys and humans (Nakamura et al., 1983; Nofzinger et al., 2002). More importantly, a wide swath of tissue within the DLPT exhibited a marked increase in metabolic activity in the lesioned subjects. This finding adds support to the notion that lesions of the PnO disinhibit activity within the DLPT and thereby increase muscle tone.

In this study, quisqualic acid lesions of the $\mathrm{PnO}$ were produced in anesthetized infants and pups were tested several hours later. As shown previously (Karlsson et al., 2005), this protocol results in the destruction of neurons at the infusion site. In the 2-DG experiment here, examination of the brain sections stained with cresyl violet again indicated loss of neurons. Examination of the autoradiographs, however, revealed areas of inactivation surrounded by halos of activation (see Figure 3B). These halos could reflect the recruitment of metabolically active glia in response to lesion-induced cell death, the disinhibition of neurons adjacent to the lesion, or even residual activation of neurons by quisqualic acid. Because we noticed that the effect of highly concentrated quisqualic acid on muscle tone develops gradually over time (presumably as neurons are killed by overexcitation), it seems unlikely that the increased EMG activity reported here, and elsewhere (Karlsson et al., 2005), can be attributed to excitation or disinhibition of neurons in surrounding tissue. This conclusion is consistent with reports in adult rats that chemical stimulation within the PnO produces atonia (Hajnik et al., 2000). Moreover, as shown here in Experiment 4, the converse is also true: inactivation of PnO neurons using the sodium channel blocker, lidocaine, produces a rapid increase in muscle tone.

Carbachol can have excitatory or inhibitory effects on state-dependent neurons within the LDT and other mesopontine nuclei (Semba, 1999). With regard to this issue, we have found that electrolytic lesions of the DLPT suppress wakefulness (Karlsson et al., 2005). Moreover, as shown here, the increased wakefulness produced by PnO lesions also increases metabolic activity within the DLPT, that scopolamine infusion into the DLPT reverses the effect of PnO 
lesions on wakefulness, and that carbachol infusion into the DLPT increases wakefulness. All together, these results provide converging evidence that, at least in infant rats, cholinoceptive neurons within the DLPT induce wakefulness when they are excited.

In the experiments in which carbachol and scopolamine were infused into the DLPT, equivalent ipsilateral and contralateral effects were found (see Figure 1 and Figure 2). In contrast, lidocaine infusion into the $\mathrm{PnO}$ evoked a significant activational effect only on the contralateral nuchal muscle (see Figure 4). These results suggest that the DLPT exerts bilateral effects on muscle tone, whereas the PnO's effects may involve only contralateral control. Whether this conclusion is consistent with a report in adult rats showing age-related differences in the bilateral inhibition of muscle tone with electrical stimulation of the PnO (Hajnik et al., 2000), remains unclear at this time.

In summary, the production of high muscle tone during DLPT activation appears mediated by the release of acetylcholine, thereby establishing a functional role for this neurotransmitter in early infancy. Moreover, the present study suggests that the DLPT and PnO comprise part of the nascent neural circuit that modulates infant muscle tone and sleep-wake cyclicity. Thus, the present results advance our understanding of the basic neural circuitry governing one of the first behavioral processes to emerge in early development.

\section{ACKNOWLEDGMENTS}

Supported by National Institute of Mental Health grants MH50701 and MH66424 (M.S.B). We thank Karl Karlsson, Adele Seelke, and Cynthia Shaw for technical assistance, and Adele Seelke and Ethan Mohns for their helpful comments on a previous version of the manuscript.

\section{ABBREVIATIONS}

2-DG, 2-deoxyglucose

ANOVA, Analysis of variance

$\mathrm{Cb}$, Cerebellum

DLPT, Dorsolateral pontine tegmentum

DC, Direct current

DR, Dorsal raphé

DT, Dorsal tegmental nucleus

EEG, Electroencephalogram

EMG, Electromyogram

IC, Inferior colliculus

LC, Locus coeruleus

LDT, Laterodorsal tegmental nucleus

Mcb, Middle cerebellar peduncle

$P$, Postnatal day

PAG, Periaqueductal gray

PB, Parabrachial nucleus

PBS, Phosphate buffered saline

$\mathrm{PnO}$, Nucleus pontis oralis

PPT, Pedunculopontine tegmental nucleus

$\mathrm{SC}$, Superior colliculus

SE, Standard error

SLD, Sublaterodorsal nucleus 


\section{REFERENCES}

Baghdoyan HA. Location and quantification of muscarinic receptor subtypes in rat pons: implications for REM sleep generation. American Journal of Physiology 1997;273:R896-R904. [PubMed: 9321865]

Blumberg MS, Seelke AM, Lowen SB, Karlsson KA. Dynamics of sleep-wake cyclicity in developing rats. Proceedings of the National Academy of Sciences 2005;102:14860-14864.

Boissard R, Fort P, Gervasoni D, Barbagli B, Luppi PH. Localization of the GABAergic and nonGABAergic neurons projecting to the sublaterodorsal nucleus and potentially gating paradoxical sleep onset. European Journal of Neuroscience 2003;18:1627-1639. [PubMed: 14511341]

Boissard R, Gervasoni D, Schmidt MH, Barbagli B, Fort P, Luppi PH. The rat ponto-medullary network responsible for paradoxical sleep onset and maintenance: a combined microinjection and functional neuroanatomical study. European Journal of Neuroscience 2002;16:1959-1973. [PubMed: 12453060]

Chase MH, Morales FR. The atonia and myoclonia of active (REM) sleep. Annual Review of Psychology 1990;41:557-584.

Corner MA, Kwee P. Cyclic EEG and motility patterns during sleep in restrained infant rats. Electroencephalography and Clinical Neurophysiology 1976;41:64-72. [PubMed: 58769]

Elazar Z, Berchanski A. Excitatory amino acids modulate epileptogenesis in the brain stem. Neuroreport 2000;11:1777-1780. [PubMed: 10852243]

Elazar Z, Feldman Z. Brainstem experimental seizures produced by microinjections of carbachol. Epilepsia 1987;28:463-470. [PubMed: 3653048]

Frank MG, Heller HC. The ontogeny of mammalian sleep: a reappraisal of alternative hypotheses. Journal of Sleep Research 2003;12:25-34. [PubMed: 12603784]

Hajnik T, Lai YY, Siegel JM. Atonia-related regions in the rodent pons and medulla. Journal of Neurophysiology 2000;84:1942-1948. [PubMed: 11024087]

Heacock AM, Fisher SK, Agranoff BW. Enhanced coupling of neonatal muscarinic receptors in rat brain to phosphoinositide turnover. Journal of Neurochemistry 1987;48:1904-1911. [PubMed: 3033155]

Jones BE. Immunohistochemical study of choline acetyltransferase-immunoreactive processes and cells innervating the pontomedullary reticular formation in the rat. Journal of Comparative Neurology 1990;295:485-514. [PubMed: 2351765]

Karlsson KA, Gall AJ, Mohns EJ, Seelke AM, Blumberg MS. The neural substrates of infant sleep in rats. PLoS Biology 2005;3:e143. [PubMed: 15826218]

Karlsson KÆ, Blumberg MS. The union of the state: Myoclonic twitching is coupled with nuchal muscle atonia in infant rats. Behavioral Neuroscience 2002;116:912-917. [PubMed: 12369810]

Karlsson KÆ, Blumberg MS. Active medullary control of atonia in week-old rats. Neuroscience 2005;130:275-283. [PubMed: 15561443]

Karlsson KÆ, Kreider JC, Blumberg MS. Hypothalamic contribution to sleep-wake cycle development. Neuroscience 2004;123:575-582. [PubMed: 14698764]

Kleitman N, Engelmann TG. Sleep characteristics of infants. Journal of Applied Physiology 1953;6:269282. [PubMed: 13108823]

Lai YY, Clements JR, Siegel JM. Glutamatergic and cholinergic projections to the pontine inhibitory area identified with horseradish peroxidase retrograde transport and immunohistochemistry. Journal of Comparative Neurology 1993;336:321-330. [PubMed: 7505295]

Lo CC, Amaral LAN, Havlin S, Ivanov PC, Penzel T, Peter JH, Stanley HE. Dynamics of sleep-wake transitions during sleep. Europhysics Letters 2002;57:625-631.

Lo CC, Chou T, Penzel T, Scammell TE, Strecker RE, Stanley HE, Ivanov P. Common scale-invariant patterns of sleep-wake transitions across mammalian species. Proceedings of the National Academy of Sciences 2004;101:17545-17548.

Lu J, Sherman D, Devor M, Saper CB. A putative flip-flop switch for control of REM sleep. Nature 2006;441:589-594. [PubMed: 16688184]

Luppi PH, Gervasoni D, Boissard R, Verret L, Goutagny R, Peyron C, Salvert D, Leger L, Barbagli B, Fort P. Brainstem structures responsible for paradoxical sleep onset and maintenance. Archives Italiennes de Biologie 2004;142:397-411. [PubMed: 15493544] 
Mohns EJ, Karlsson KÆ, Blumberg MS. The preoptic area and basal forebrain play opposing roles in the descending modulation of sleep and wakefulness in infant rats. European Journal of Neuroscience 2006;23:1301-1310. [PubMed: 16553791]

Nakamura RK, Kennedy C, Gillin JC, Suda S, Ito M, Storch FI, Mendelson W, Sokoloff L, Mishkin M. Hypnogenic center theory of sleep: no support from metabolic mapping in monkeys. Brain Research 1983;268:372-376. [PubMed: 6871691]

Nofzinger EA, Buysse DJ, Miewald JM, Meltzer CC, Price JC, Sembrat RC, Ombao H, Reynolds CF, Monk TH, Hall M, Kupfer DJ, Moore RY. Human regional cerebral glucose metabolism during nonrapid eye movement sleep in relation to waking. Brain 2002;125:1105-1115. [PubMed: 11960899]

Seelke AMH, Blumberg MS. Thermal and nutritional modulation of sleep in infant rats. Behavioral Neuroscience 2005;19:603-611. [PubMed: 15839806]

Seelke AMH, Karlsson KÆ, Gall AJ, Blumberg MS. Extraocular muscle activity, rapid eye movements, and the development of active and quiet sleep. European Journal of Neuroscience 2005;22:911-920. [PubMed: 16115214]

Semba, K. Development of central cholinergic systems. In: Tohyama, A., editor. Ontogeny of transmitters and peptides in the central nervous system. London: Elsevier; 1992. p. 33-62.

Semba, K. The mesopontine cholinergic system: a dual role in REM sleep and wakefulness. In: Lydic, R.; Baghdoyan, HA., editors. Handbook of behavioral state control: molecular and cellular mechanisms. Boca Raton, FL: CRC; 1999. p. 161-180.

Semba K, Fibiger HC. Afferent connections of the laterodorsal and the pedunculopontine tegmental nuclei in the rat: a retro- and antero-grade transport and immunohistochemical study. Journal of Comparative Neurology 1992;323:387-410. [PubMed: 1281170]

Shiromani PJ, Armstrong DM, Gillin JC. Cholinergic neurons from the dorsolateral pons project to the medial pons: a WGA-HRP and choline acetyltransferase immunohistochemical study. Neuroscience Letters 1988;95:19-23. [PubMed: 2465510]

Xi MC, Morales FR, Chase MH. Evidence that wakefulness and REM sleep are controlled by a GABAergic pontine mechanism. Journal of Neurophysiology 1999;82:2015-2019. [PubMed: 10515993]

Xi MC, Morales FR, Chase MH. Interactions between GABAergic and cholinergic processes in the nucleus pontis oralis: neuronal mechanisms controlling active (rapid eye movement) sleep and wakefulness. Journal of Neuroscience 2004;24:10670-10678. [PubMed: 15564583] 
A
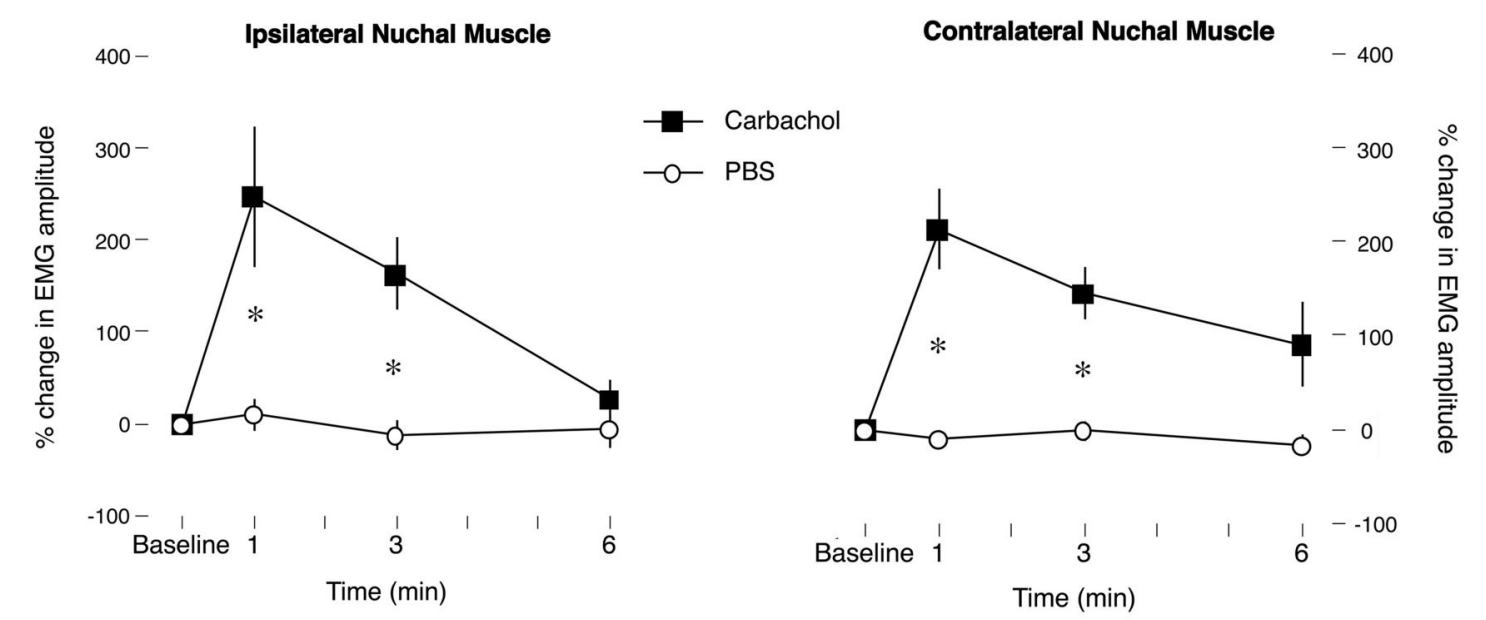

B
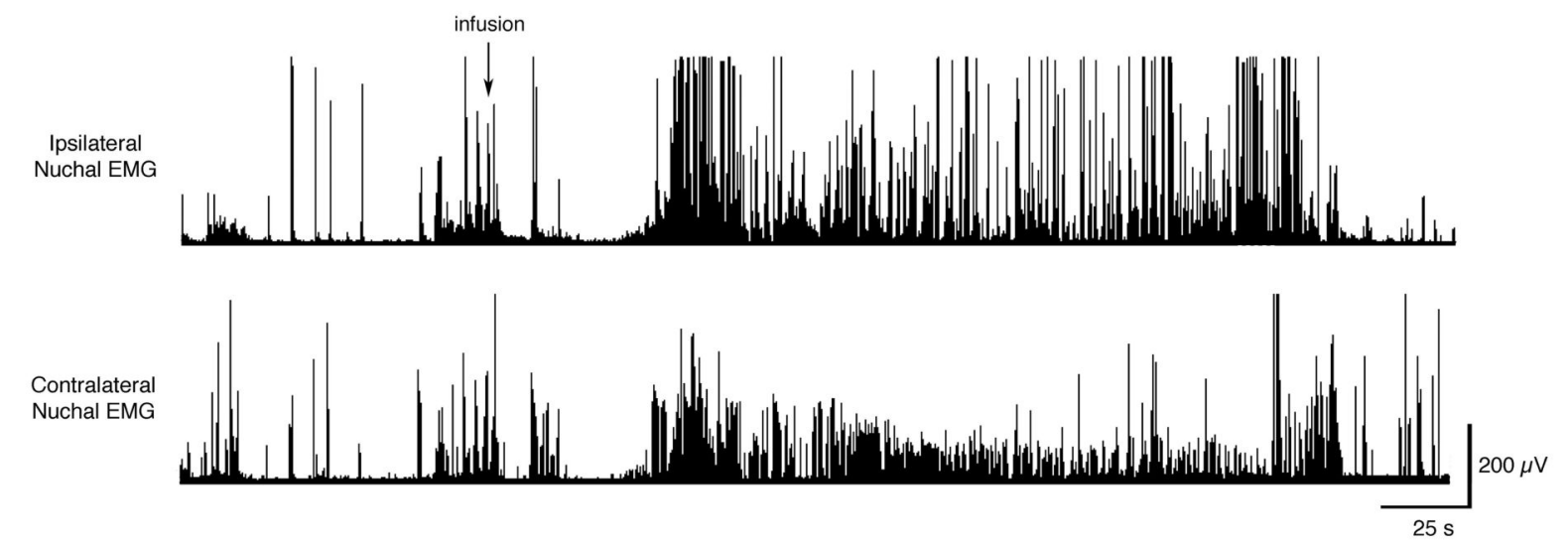

C

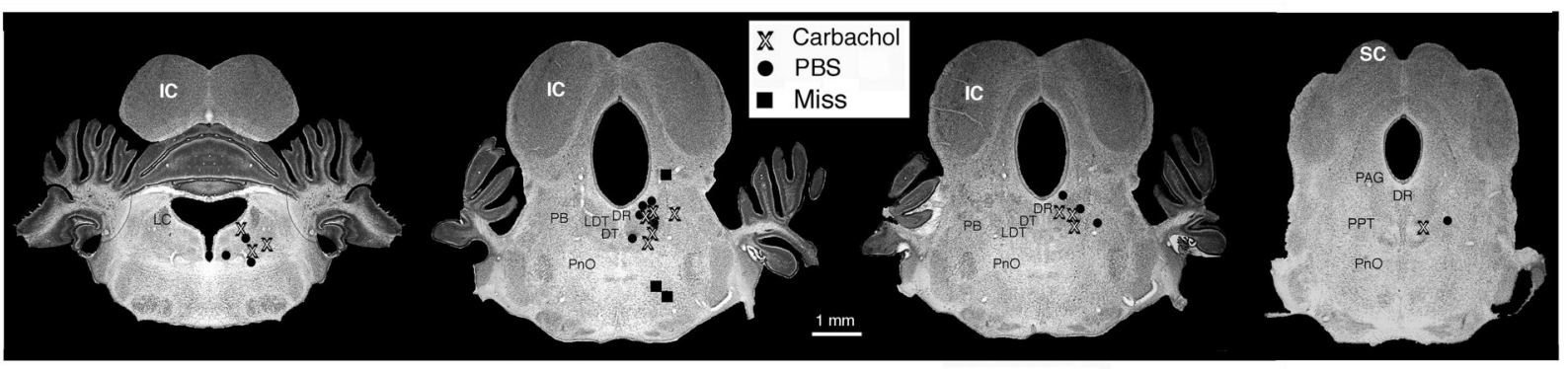

Figure 1.

Carbachol infusion into the dorsolateral pontine tegmentum produces increased nuchal muscle tone in P8-10 rats. (A) Percentage change in nuchal EMG amplitude from baseline after ipsilateral $(n=10)$ or contralateral $(n=6)$ infusion of the cholinergic agonist carbachol or vehicle (PBS). Amplitudes were averaged over the 10-s period immediately before infusion and at 1 , 3 , and 6 min after the infusion. * Significant difference between groups. $\mathrm{N}=12$ subjects per group. Mean \pm SE. (B) Representative ipsilateral and contralateral nuchal EMG responses to infusion of carbachol $(22 \mathrm{mM})$. The arrow indicates the onset of the infusion $(0.1 \mu \mathrm{L}$ over 20 s). (C) Coronal sections of the brainstem to indicate infusion sites. Carbachol infusion sites are marked by Xs; vehicle (PBS) infusion sites are marked by circles; misses (i.e., carbachol 
infusion sites where muscle tone was not increased) are marked by squares. Abbreviations: IC, inferior colliculus; LC, locus coeruleus; DR, dorsal raphé; LDT, laterodorsal tegmental nucleus; PB, parabrachial nucleus; DT, dorsal tegmental nucleus; PnO, nucleus pontis oralis; PAG, periaqueductal gray; PPT, pedunculopontine tegmental nucleus; $\mathrm{SC}$, superior colliculus. 
A

100 Ipsilateral to Infusion

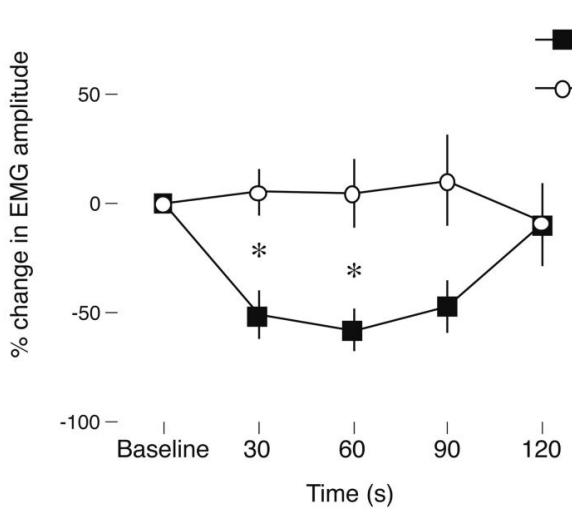

Contralateral to Infusion $-100$

Scopolamine

- PBS

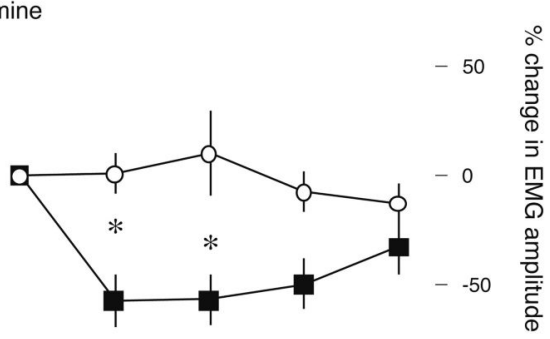

Baseline $\quad 30 \quad 60 \quad 90 \quad 130--100$

B

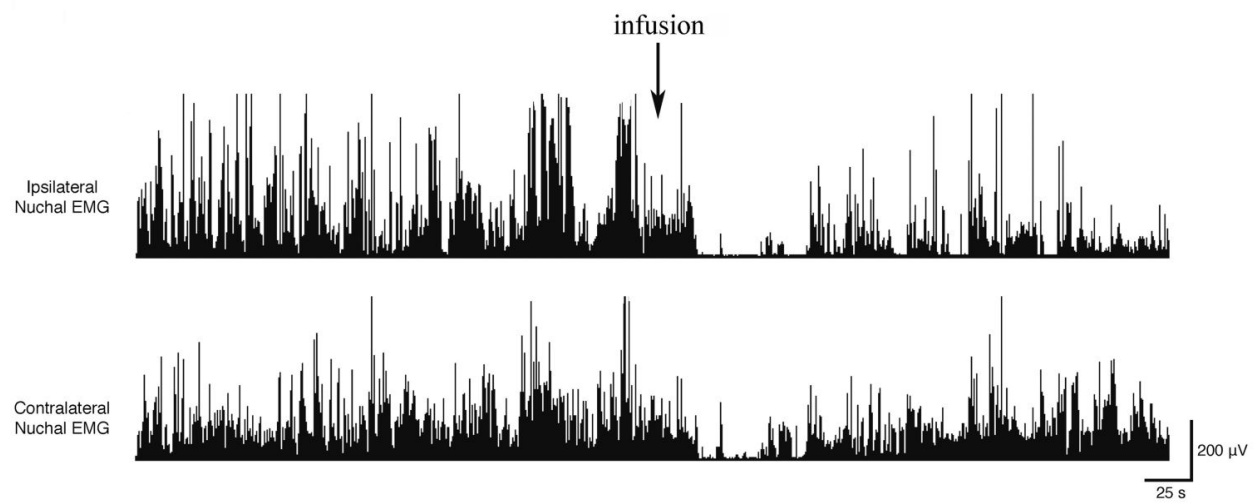

C

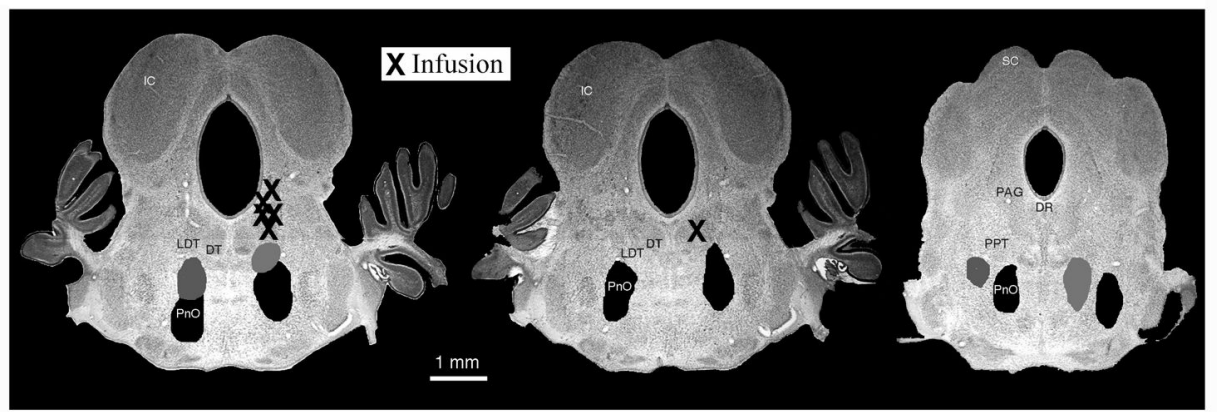

Figure 2.

Infusion of scopolamine into the dorsolateral pontine tegmentum (DLPT) reverses the effects of lesions of the nucleus pontis oralis (PnO) on nuchal muscle tone in P8-10 rats. (A)

Percentage change in ipsilateral and contralateral nuchal EMG amplitude from baseline after infusion of the cholinergic antagonist scopolamine or vehicle (PBS). Both scopolamine and vehicle were infused at the same site with order counterbalanced. * Significant difference between groups. $\mathrm{N}=6$ subjects per group. Mean $\pm \mathrm{SE}$. (B) For a representative subject, ipsilateral and contralateral nuchal EMG responses to infusion of scopolamine $(10 \mathrm{mM})$ into the DLPT. The arrow indicates the onset of the infusion $(0.1 \mu \mathrm{L}$ over $20 \mathrm{~s})$. (C) Coronal sections of the brainstem to indicate lesion and infusion sites. The smallest and largest lesions of the 
$\mathrm{PnO}$ within each brain section are denoted by the gray and black areas, respectively. Infusion sites are marked by Xs. Abbreviations as in Figure 1. 
A

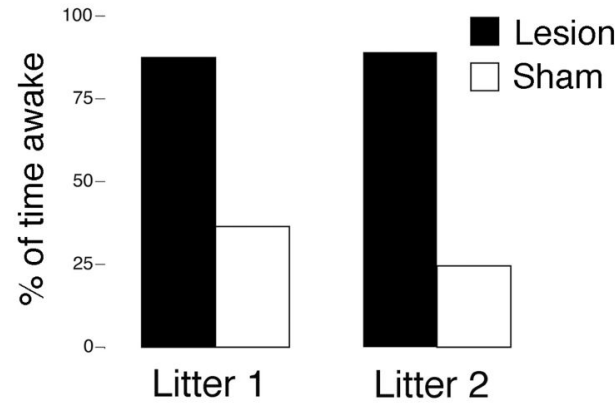

C
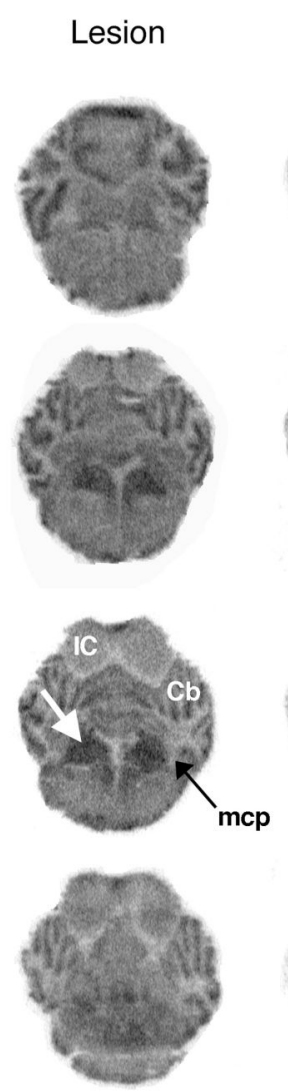

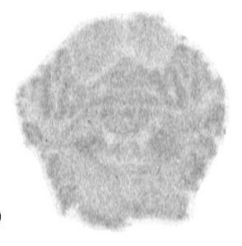

Litter 1

Sham
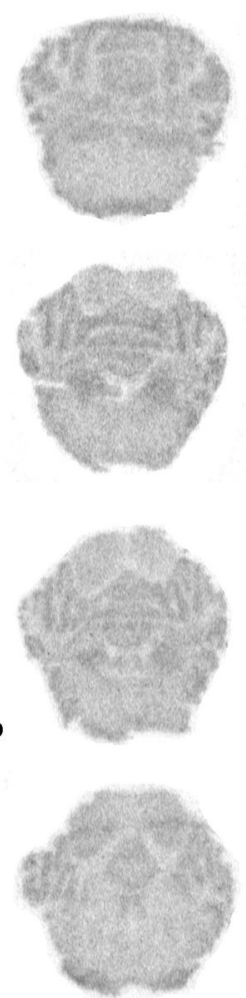

B

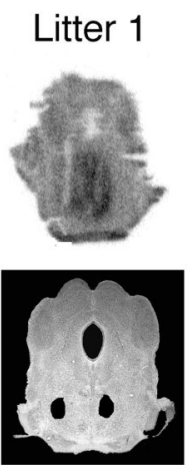

\section{Litter 2}
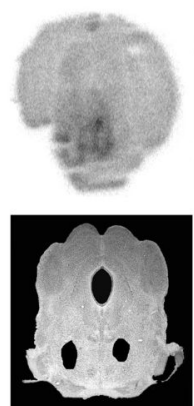

Figure 3.

Metabolic activity within the dorsolateral pontine tegmentum (DLPT) increases after lesions of the nucleus pontis oralis $(\mathrm{PnO})$ in $\mathrm{P} 8$ rats. Two rats from two litters (denoted Litter 1 and Litter 2) received chemical lesions of the PnO; two littermates received sham lesions. Each pup was injected with 2-DG and then allowed to cycle normally between sleep and wakefulness for $45 \mathrm{~min}$ before its brain was removed. (A) Percentage of time awake for the lesion (filled bars) and sham (unfilled bars) pups during the 45-min period after injection of 2-DG. (B) Top row: 2-DG autoradiographs depicting lesions within the PnO for each of the two pups. Lesion sites are indicated by areas of inactivation surrounded by halos of increased activation. For one site (Litter 1), the syringe track can also be seen. Bottom row: Lesion sites as determined by 
inspection of sections stained with cresyl violet. In both cases, filled regions indicate areas devoid of neurons. (C) 2-DG autoradiographs for each of the four subjects. The white arrow indicates increased metabolic activation within a region of the DLPT that includes the parabrachial nucleus and laterodorsal tegmental nucleus. Overall levels of metabolic activity are higher in the lesion pups in relation to the shams. Abbreviations: IC, inferior colliculus; $\mathrm{Cb}$, cerebellum; mcb, middle cerebellar peduncle. 
A
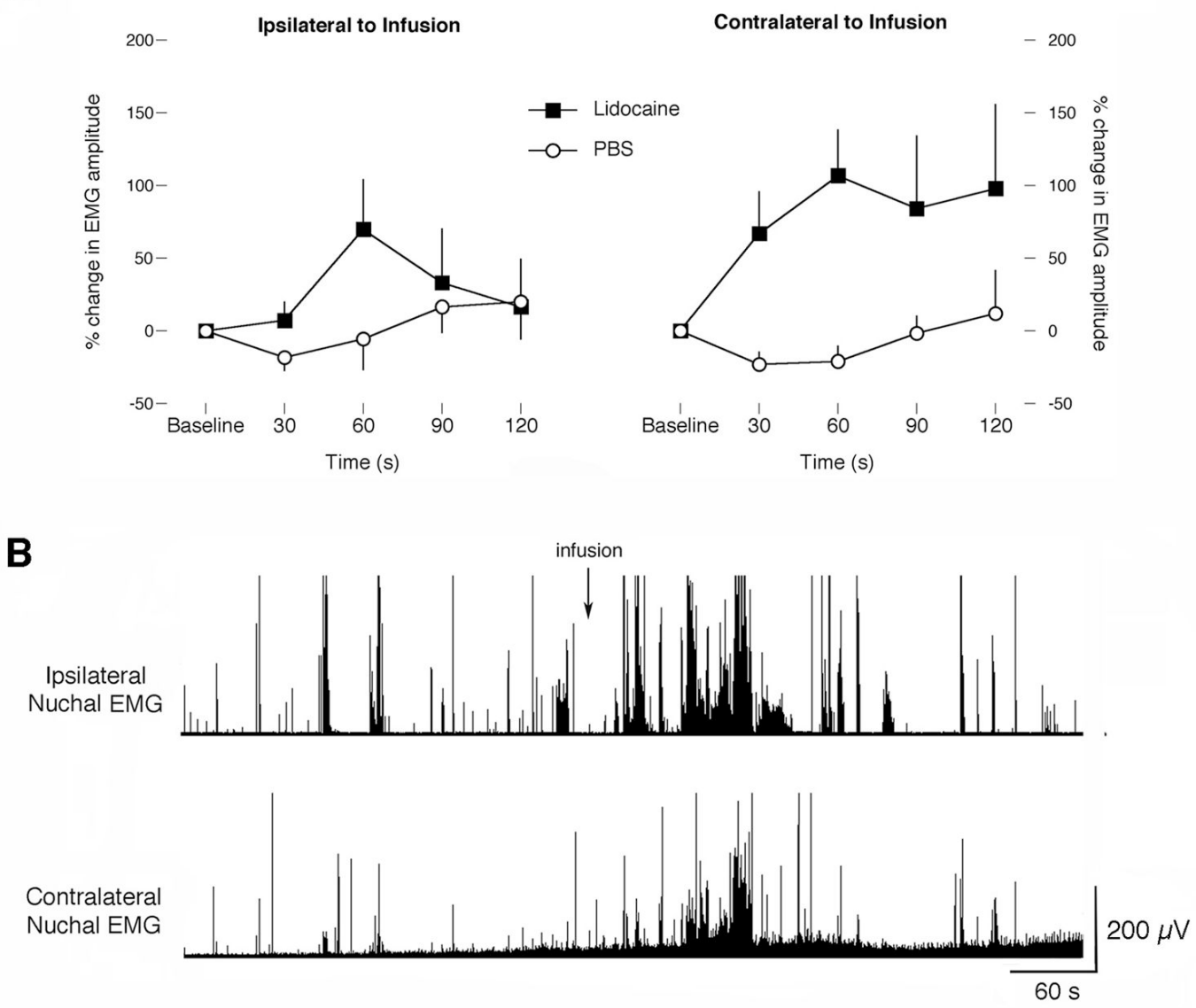

\section{C}

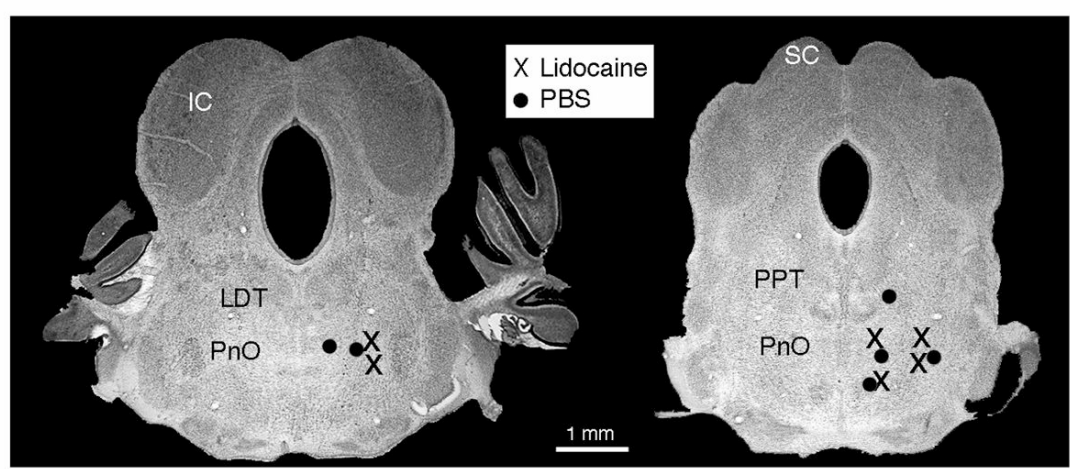

Figure 4.

Infusion of lidocaine into the nucleus pontis oralis $(\mathrm{PnO})$ produces increased nuchal muscle tone in P8-10 rats. (A) Percentage change in ipsilateral and contralateral EMG amplitude from baseline after infusion of lidocaine (2\%) or vehicle (PBS). (B) Representative nuchal EMG responses to infusion of lidocaine. The arrow indicates the onset of the infusion $(0.2 \mu \mathrm{L}$ over $15 \mathrm{~s}$ ). (C) Coronal sections of the brainstem to indicate infusion sites. Lidocaine infusion sites are marked by Xs; vehicle infusion sites are marked by filled circles. Abbreviations as in Figure 1. 